\title{
E-Learning as a Core Component of the Instruc- tional Design Profession
}

\author{
http://dx.doi.org/10.3991/ijac.v5i3.2204 \\ Tome Martinez, Paula Cummins, Wilhelmina Savenye, and Justin Shewell \\ Arizona State University, Tempe, Arizona
}

\begin{abstract}
Periodic assessment and evaluation is an important part of any successful program. This paper presents the findings of a needs assessment which examined the influence of e-learning and technical skill development in the area of educational technology with specific attention paid to the field of instructional design. A three-phase mixed methods approach was employed to carryout this assessment. Findings indicate that there is a strong perception among the participants that e-learning is a core component of the instructional design profession. The results of the study give a clear indication that e-learning is a significant influence on current instructional design operations. Therefore, it is necessary for students to acquire the skills required to successfully operate these programs. Recommendations were developed that can allow programs to be more responsive to current trends impacting the profession.
\end{abstract}

Index Terms-E-Learning, Instructional Design, Needs Assessment, Program Review, Workforce Preparation

\section{INTRODUCTION: EDUCATIONAL TECHNOLOGY PROGRAMS}

Educational technology is often thought of in either broad or narrow terms depending on the audience. This dual nature reflects the broad background of individuals that encompass the profession. However, it also reflects the extreme lack of consensus of what topics (tools, technology, learning, etc.) encompass the field [1].

In the most recent definition for the profession, the Association for Educational Communications and Technology (AECT) defined educational technology as, “...the study and ethical practice of facilitating learning and improving performance by creating, using, and managing appropriate technological processes and resources.” [2].

Academic professionals in educational technology, instructional technology and instructional design have used this as well as other definitions to help shape their program(s) by modifying course and program curriculum [3], [4].

While foundational definitions give some insight into the nature of a topic, getting the views of people in the profession can provide valuable insight about current practices and trends. When surveying a pool of instructional designers, design and development was found to consume the largest portion of an instructional design professional's time with almost an equal share being devoted to project management and administrative processes [5]. Further, the wide variance of job environments creates additional complexities that current academic programs may not be able to respond to given resources constraints, particularly in a recessionary environment [6].
The lack of adequate responsiveness to these complexities along with rapid changes in technological tools and processes has led to opinions like those of Dr. Ellen Wagner [7] who offers this opinion on the ability of academic programs to properly prepare student for the field:

The not so good news is that the alignment between preparation and practice has continued to bifurcate. Many of the things that instructional design programs prepare people to do are not necessarily the same set of skills that employers look for when hiring an instructional designer.

While previous research has shown that specific academic programs have been responsive to some changes, academic programs as a whole have clearly not satisfied the expectations of Dr. Wagner. With the United States slowly coming out of a severe economic recession, the resulting economic pressures put particular strains on labor markets which, in turn, led to significant changes in the common set of skills and abilities needed to obtain and be successful in the specific labor markets that one would generally explore during and/or after graduating from an educational technology program. Until 2008, the use of elearning as the chosen method of delivering content and instruction has steadily increased with the most recent slight downturn expect to reverse in the coming years [8]. While not specifically identifying the most recent economic recession as the cause of this downturn in elearning usage, it would not be out of the question to correlation between these two events with expectations to positively correlate with increased economic levels.

An investigation into the presence of e-learning as a content and instructional delivery method in organizations as well as other current trends can help determine what changes, if necessary, educational technology and related programs can carry out in order to make them more responsive to these changes in the field. This study was comprised of a needs assessment that responded to and provided information regarding the following four areas in determining the overall needs for the expansion.

1. Does the higher education \& business community have a need for e-learning design and development skills? How strong is this need?

2. What are the specific technical skills used in selected job descriptions that are within the ideal target market for graduates? How important are these specific technical skills in gaining employment in these positions? 
3. How can Educational Technology programs best accommodate changing interests into creating courses that are more responsive to current changes in educational technology among the selected labor markets in higher education and business?

4. What are other areas in which Educational Technology programs can adapt to current labor needs that can make program graduates better equipped to have successful careers in the targeted labor markets?

\section{RESEARCH: ASSESSING THE VALUE OF E-} LEARNING IN THE INSTRUCTIONAL DESIGN PROFRESSION

\section{A. Participants}

In the course of completing this needs assessment, selected groups were specifically identified based on their experience within the field of educational technology either as a student, a practitioner, or in the case of graduates of an educational technology or related program, both. This involved the identification of two main groups:

1. Current Students in an educational technology or related program, and

2. Graduate of one or more educational technology or related programs

The current students as well as the graduates were associated, in some capacity, with at least one program from a major university in the southwestern United States.

\section{B. Method and Procedures}

A mixed-method process was used to gather data for this needs assessment. This data gathering process was divided into three phases. The first phase involved the gathering of third-party existing data and records with the second phase involved the release of an online survey. The final phase involved conducting formal and informal interviews.

Existing data and records were aimed at providing data concerning two aspects. Specifically, an analysis comparing current programs that focus on online learning which are offered at other educational institutions was conducted in order to gain a perspective of what is being offered at other institutions in North America. This analysis can be used to provide a structural basis for seeing exactly how other institutions have dealt with the incorporation of online learning in their programs. In addition to this preexisting data of online programs, a set of current job announcements was collected. These job announcements represented targeted areas for graduates of certificate and masters programs in educational technology or a similar program.

Participants were recruited to participate in an online survey via an educational technology e-mail list. The members of the list include current students, graduates as well as faculty, staff and other individuals involved in the educational technology programs. Preceding the survey was an acknowledgement of the participants' informed consent. Once in the survey, the participants were asked to identify themselves as a current student, graduate, or neither. Depending on their answers to this initial ques- tion, the participants were re-directed, if necessary, to a survey that contained questions which were developed to draw upon the specific experiences of that group.

As part of the online survey, participants were asked to provide contact information for the possibility of a followup interview. This will give the participant the opportunity to provide addition information and elucidation that was not addressed in the survey. Following a specific period for survey participation, a list of participants who submitted contact information was collected. Those that gave an e-mail address were sent a copy of the follow-up questions with the option given to the participant to either respond directly to the questions and send them back via e-mail, or provide the evaluators with a phone number (if nor already provided) and specific times when they can be contacted via telephone for an interview. Using a constant comparative method described in Leech \& Onwuegbuzie [9], codes will be developed abductively with the expectation of gaining further insight into the issue that pertain to e-learning, instructional design and improving educational technology programs.

\section{RESEARCH FINDINGS From the ThreE PhASES}

\section{A. Phase 1: Existing Data and Records}

An existing data set was obtained which presented information on a total of 34 certificate programs from higher education institutions in the United States and internationally. Programs were selected based on similarities in course curriculum, professional affiliations, and other publically available program information. In an analysis of this program information, it was determined that a minor amount of e-learning programs focus on the k-12 teachers and administrators. However, for those institutions which have an e-learning certificate program that focuses on other areas (i.e., business, higher education, private nonprofits, etc.) a few patterns emerged. First, all have required courses focusing generally on instructional design and development. Some of these required courses focus on online instructional design while other programs (not all) have an additional course on online instructional design and development.

Secondly, almost all of the programs presented have required coursework pertaining to learning technical skills. However, the level of involvement in actually facilitating specific learning of fundamental technical programs to help a person succeed in the field varied and can not be verified from the information obtained. Third, other coursework topics that were less frequently included on the collection of programs include online assessment, copyright and intellectual property, needs assessment, information literacy, performance improvement, training and adult learning. Finally, common program outcomes for students include being able to design and develop instructional materials (some specifically mention online design and development) and being able to implement applicable learning theory into the instructional design process. Other outcomes that were less often cited include the ability to manage instructional design projects, implement social networking tools, educational evaluation, and improving productivity.

A search of job announcements offered for positions in Arizona were collected at regular intervals over a period of one month. Duplicate job announcements for the same 
position in the same organization were counted only once. A total of 51 job announcements were collected over the selected time period. Some of the announcements stated required duties that were in concert with instructional design principles such as knowledge of the ADDIE process (occasionally), designing and developing instructional materials for both an online platform and other offline mediums (all). Further, team collaboration, writing, communicating with clients and subject-mater experts, as well as providing some aspects of technical support were other duties that were mentioned from occasionally to very frequently.

Explicit attention was paid to the specific technical programs that were stated in each job announcement. The main purpose of this particular task was to identify the specific programs that are in demand from employers. The count was separated into required and preferred rows depending on where the program was noted in the job announcement. Preferred was used to describe program knowledge that is optional, but desired for an ideal candidate. From the data, a total was calculated as well as a percentage of the program being mention as a total of the entire collection. The most common program set was Microsoft (MS) Office (23 required, 1 preferred, 47.06\%). In this case, a specific program or programs of the office suite may have been mentioned or the entire suite may have been mentioned. Learning Management Systems (LMS) were the next most common technical programs (6 required, 5 preferred, $21.57 \%$ ). The LMS column included any system such as BlackBoard, Moodle, etc. Flash is the most common standalone program with an equal number mentioning the program as required or preferred (5 required, 5 preferred, 19.61\%).

\section{B. Phase 2: Online Survey}

Three groups were identified as potential participants for the survey. They included current students, graduates and other stakeholders who are not current students or graduates of an educational technology or similar program. The group for graduates was divided into groups based on the possibility that they may have hiring or management responsibilities. The survey aimed to capture the attitudes and options of individuals in these selected groups towards online learning in educational technology, their attitude of specific technical programs as it related to the career in educational technology and/or their organization and their opinion of possible program changes. The following information represents a summary of key findings from the online survey.

A total of 22 current students participated in the survey making this the largest of the three groups. Approximately 71.4 percent of the respondents in this group are at the $\mathrm{PhD}$ level with the remaining being made up of Masters (19\%) and certificate students (14.3\%). Most (68.2\%) have taken more than six educational technology courses. The averages of all of the responses for each of the questions seem to indicate that they Agree with the statement to a certain degree, but do not claim go as far as to strongly agree. When presented with a list of technical program and programming languages participants were asked to respond based on their perceived importance to their future career. These were identified based on the analysis of job announcements. Based on the average, the most important technical skills are MS Office, Learning Management Systems (LMS) and Captivate.
With respect to the importance of copyright and intellectual property instruction, an overwhelming majority (91\%) Agree or Strongly Agree with the statement that instruction on copyright and intellectual property right be required for students in all EDT programs. There were no participants who Disagreed or Strongly Disagreed with the statement. Further, when asked if a course on this topic be required for masters and $\mathrm{PhD}$ students, a majority (59.1\%) either Agree or Strongly Agree.

Lastly, open-ended questions were provided to ask participants their thoughts towards additional skills not previously noted that may be useful towards employment in the field. Common responses obtained from the questions concerning additional skills include collaboration skills, communication and writing skills and project management skills (including project management software). Other responses mentioned include programming languages, video editing, contract writing, consulting and classroom or training experience. When asked for advice for the educational technology programs, common responses from participants include more research opportunities for students (and some funding), a need for instruction on important technical skills and, overall, doing a better job to "match" the career to student preparation.

A total of 19 graduates participated in the survey. The majority of these students attended at least one program from a major university in the southwestern United States. For the purposes of further analysis, this set of participants was divided into two groups depending on the existence of managerial duties. Eight of the participants from this group do not have managerial or hiring responsibilities (manager sub-group) with the remaining 11 participants having some sort of managerial or hiring duties. The level of these duties was not explored further in the survey. With regards to the employee sub-group without managerial or hiring duties all of the respondents were female. Most (6) have completed the masters degree. When presented with a list of technical program and programming languages participants were asked to respond based on their perceived importance to their career. These were identified based on the analysis of job announcements. Based on the average, the most important technical skills are MS Office, Learning Management Systems, SharePoint, Photoshop and Acrobat. With regards to the subgroup without managerial or hiring duties $100 \%$ of the respondents were female. Most of this sub-group (6) have completed the masters degree.

When presented with a list of technical program and programming languages participants were asked to respond based on their perceived importance to their career. These were identified based on the analysis of job announcements. Based on the average, the most important technical skills are MS Office, Learning Management Systems, SharePoint, Photoshop and Acrobat. Additional questions proposed to participants included questions about additional programs and/or formats and the importance of instruction on copyright and intellectual property. With respect to the importance of copyright and intellectual property instruction, seven out of eight (87.5\%) Agree or Strongly Agree with the statement that instruction on copyright and intellectual property right be required for students in all educational technology programs. There were no participants who Disagreed or Strongly Disagreed with the statement. Further, when asked if a course on this topic be required for masters and PhD students, a five out 
of eight (62.5\%) either Agree or Strongly Agree. Two respondents disagreed with the statement.

Lastly, open-ended questions were provided to ask participants their thoughts towards additional skills not previously noted that may be useful towards employment in the field. Common responses obtained from the questions concerning additional skills include collaboration skills, communication and project management skills. Other responses mentioned include programming languages, gaming, contract writing, adult learning and instructional design philosophy. When asked for advice for educational technology programs, common responses from participants include offering continuing education opportunities at reasonable rates, exposure to web 2.0 tools, including more opportunity for synchronous session in online courses, and more courses on performance improvement.

With regards to the graduate group with managerial or hiring duties all of the respondents were female. Most (10) have completed the masters degree. When presented with a list of technical programs and programming languages, participants were asked to respond based on their perceived importance to their career. These were identified based on the analysis of job announcements. Based on the average, the most important technical skills are MS Office, Learning Management Systems and Articulate. Additional questions proposed to participants included questions about additional programs and/or formats and the importance of instruction on copyright and intellectual property. With respect to the importance of copyright and intellectual property instruction, all respondents Agree or Strongly Agree with the statement that instruction on copyright and intellectual property right be required for students in all educational technology programs. Further, when asked if a course on this topic be required for masters and $\mathrm{PhD}$ students, six out of 11 either Agree or Strongly Agree. Four respondents Disagreed with the statement.

Lastly, open-ended questions were provided to ask participants their thoughts towards additional skills not previously noted that may be useful towards employment in the field. Common responses obtained for the questions concerning additional skills include communication and project management skills. Other responses mentioned include collaboration and writing skills. When asked for advice for educational technology programs, conflicting responses emerged from respondents who wanted to keep the focus on learning theory versus those that wanted to de-emphasize learning theory and offer more opportunities to learn technical skills. Other ideas mentioned include offering more online courses and preparing students better for managerial positions.

\section{Phase 3: Participant Interviews}

Five survey participants responded to four interview questions related to e-learning and its incorporation into educational technology programs. Using a constant comparative method to analyze the data set of responses from the participants, themes emerged regarding communication as well as learning theory versus technical skills.

Communication issues within their organization specifically pertaining to collaborative efforts were expressed by all of the participants. A current PhD student said communication was the challenge, explaining that, "Creating a good system for communicating with SMEs [subject matter experts] and managing an ongoing relationship with them through course development.”

Project management was another challenge mentioned by a program graduate, saying that, "I had no project management experience and did not learn about it [from my academic program]. While several schools offer a course on [project management], we did not have a similar course. As an instructional designer, we are expected to manage projects at times.”

When considering hiring an instructional designer, a current PhD student said his first objective would be team dynamics, verifying whether the potential employee is mentally and emotionally capable of working well on a team.

The dichotomy of technology verses learning theory was also another theme that was present among the opinions of the interview participants. Respondents were questioned to determine what percentage of the instructional designer job comprises computer software knowledge and skills? Respondents indicated a range from 50\% to $90 \%$ depending on the assignment or job. This would indicate that at least half to the vast majority of an instructional designer's job involves interacting with various technical programs which requires one to have the skills to operate these programs. A current student cited the size of the organization as the determining factor. He explained:

If it is a 4,000+ employee company who has specialists that can write code, then I am not really concerned about skills. If it is 20 person shop, then the requirement to use computers grows immensely. At my job, where we have people who can take hand drawn screens and "word pictures" and turn them into tangible output, I go back to question 2, above, where I realize we continue to look for people with computer skills over learning theory.

Other considerations would depend on the job. A program graduate noted that, "It's easier to get up to speed on instructional design and learning science than it is to acquire good software design and computer science skills."

Another current student said that he initially placed greater importance on software skills when hiring, assuming a SME would provide all needed knowledge. However, due to work experience, he explained,

I will be grilling future candidates on their knowledge of learning theory! I realize one of the faults of my organization is that we have hired for software skills, not learning theory. The theory the employees do have is extremely limited "from the textbook” without any real world application to speak of.

While one program graduate stated that instructional and learning theory knowledge to be of most concern, another alumnus said that computer skills would be of first consideration, "I figure if they are going for an ID job than 
they hopefully have the education. But if they don't have computer skills in Photoshop, Flash, Captivate, Camtasia, etc., I would be spending a lot of time teaching them and that would not be productive."

A program graduate agreed that, "It is helpful if the candidate already possess computer software knowledge and skills. However, he/she must be quick learner especially with the changing nature of the field where new technology is introduced so frequently."

\section{DISCUSSION AND CONCLUSIONS}

The purpose of this needs assessment was to investigate the demand for e-learning instructional design in the current instructional design professional field, to see the impact of specific technical skills and their current emphasis in educational technology programs. Overall, the results from the evaluation suggest that e-learning instructional design is a significant part of the current instructional design profession. In addition, the demand for developing in-demand technical skills is very high. The following represents a more detailed discussion of the evaluation results based on each evaluation question.

1. Does the higher education \& business community have a need for online design and development skills? How strong is this need?

A common theme from a search of job announcements was the presence of job duties that focus on aspects of designing and/or developing online instructional materials. In addressing their attitudes towards e-learning instructional design in their current or futures careers, survey respondents overall agreed with the statement that elearning will be a significant part of their profession. This relationship is not surprising and indicates that the survey participants overall were aware of the current demand in the profession.

2. What are the specific technical skills used in selected job descriptions that are within the ideal target market for graduates? How important are these specific technical skills in gaining employment in these positions?

Both the results of job announcements as well as the results from survey respondents among all groups indicate a near consensus around a set of technical programs which are important to gaining and keeping employment in the profession. Comparing these data to the current program curriculums, the opportunity for students to use MS Office programs such as Word, Excel and PowerPoint is significant if one were to complete an educational technology program.

3. How can Educational Technology programs best accommodate changing interests into creating courses that are more responsive to current changes in educational technology among the selected labor markets in higher education and business?

Specific attention was paid to e-learning within instructional design since there was an indication, from survey data, that there is a demand for focused e-learning instructional design. This demand could be in the form of courses, training workshops or integrating instruction into current educational technology courses.

When asked if a hypothetical graduate certificate in elearning instructional design should be fully online, the majority of alumni responded positively to the proposed program delivery method. A majority of current students, however, responded negatively towards the proposed delivery method. This difference in opinion could be from several factors. First, current students may believe that the current coursework has enough opportunity for online instructional design and development to mitigate this need. Also, alumni may have graduated many years ago and may not have received the same amount of opportunity for online instructional design as current students.

Another area was the development of technical skills. Survey results show that the development of in-demand technical skills is a major point of emphasis. Some did not feel that current educational technology programs deliver enough opportunity to develop these skills. Others fear that more emphasis on technical skills will result in less emphasis on learning theory. It is important to strike a balance between these two areas. Based in the survey data, the most important technical program is MS Office. There may be a variety of opportunities to develop technical skills in this program in the current educational technology programs. However, faculty may want to provide more opportunity to use specific tasks with this software suite that can be directly transferred to the career.

Lastly, in order maximize course offerings and make sure that they have sufficient enrollment it is necessary to collaborate among different departments within and outside of Colleges/Schools of Education. For instance, training and performance improvement courses may be useful to a student in the business school that is focusing on human resource development. The survey results showed a need for instruction and even a required course on copyright and intellectual property rights. Courses may be offered in other departments with can satisfy this need. Collaboration between the members of these departments and educational technology programs can facilitate a course that meets the needs of educational technology students and from an administrative perspective, creates a new steam of students for that course.

4. What are other areas in which Educational Technology programs can adapt to current labor needs that can make program graduates better equipped to have successful careers in the targeted labor markets?

This question relates to other areas outside of formal programmatic or curriculum changes that the organizational structure in the educational technology programs where changes could be made to help current and former students of these programs. One respondent stated that the program was not "matching" the education of the program graduate to the needs of the current marketplace. If educational technology programs are to remain a source of highquality graduates for the professional markets then this must change. Given the current budget and human resource constraints that currently exist in nearly all institutions of high education, particularly public colleges and universities, it is difficult to envision large changes. Luckily, large changes may not be needed. 
Educational technology programs can make students more aware of professional organizations in the area where they can receive information from support and networking to instruction on topics and issues that may increase the chances of success in the profession. There are many connections that faculty have made within these organizations. This does take some effort, but does not have significant external monetary costs to the program while potentially providing significant dividend for current students as well as opening the door for potential students which inevitably helps the evolution of educational technology programs.

\section{REFERENCES}

[1] Garrison, D. R., and T. Anderson. E-learning in the 21st century: A framework for research and practice. 1st. New York: Routledge, 2003. 33-34. http://dx.doi.org/10.4324/9780203166093

[2] Richey, R. "Reflections on the 2008 aect definitions of the field." TechTrends. 52.1 (2008): 24-25. http://dx.doi.org/10.1007/s11528008-0108-2

[3] Donaldson, J.A. "Definition to practice: Translating the definition into a standards-based it program." TechTrends. 53.5 (2009): 2933. http://dx.doi.org/10.1007/s11528-009-0321-7

[4] Robinson, R. "Using the definition in foundation building." TechTrends. 53.5 (2009): 34-40. http://dx.doi.org/10.1007/s11528$\underline{009-0322-6}$

[5] Cox, S., \& Osguthorpe, R. (2003). How do instructional design professionals spend their time? TechTrends, 47(3), 29, 45-47. http://dx.doi.org/10.1007/BF02763476

[6] Larson, M., and B. Lockee. "Instructional design practice: Career environments, job roles, and a climate of change." Performance
Improvement Quarterly. $17.1 \quad$ (2004): $22-40$. http://dx.doi.org/10.1111/j.1937-8327.2004.tb00300.x

[7] Wagner, E. "Essay: In search of the secret handshakes of id." Journal of Applied Instructional Design. 1.1 (2011): 33-37.

[8] Green, M., and E. McGill. State of the Industry, 2011. Alexandria: ASTD Research, 2011.

[9] Leech, N. L., \& Onwuegbuzie, A. J. (2007). An array of qualitative data analysis tools: A call for data analysis triangulation. School Psychology Quarterly, 22(4), 557-584. http://dx.doi.org/10.1037/1045-3830.22.4.557

\section{AUTHORS}

Tome Martinez is with the Division of Educational Leadership and Innovation, Arizona State University, Tempe, AZ 85287 USA (e-mail: tome.martinez@asu.edu).

Paula Cummins was with the Division of Educational Leadership and Innovation, Arizona State University, Tempe, AZ 85287 USA (e-mail: pjcummins@asu.edu).

Wilhelmina Savenye is with the Division of Educational Leadership and Innovation, Arizona State University, Tempe, AZ 85287 USA (e-mail: willi.savenye@asu.edu).

Justin Shewell is with the Division of Educational Leadership and Innovation, and the American English and Culture Program, Arizona State University, Tempe, AZ 85287 USA (e-mail: jshewell@asu.edu).

This article is an extended version of a paper presented at the conference ICELW2012, held June 2012, at Columbia University, in New York, NY, USA. Manuscript received 01 April 2012. Published as resubmitted by the authors. 05 August 2012 